\title{
Comics tattoo como objeto biográfico ${ }^{1}$
}

\author{
João Batista Freitas Cardoso' \\ I - USCS \\ São Caetano (SP), Brasil
}

Resumo: O artigo tem como principal objetivo compreender a Comics Tattoo como um objeto biográfico que visa a preservar e comunicar a memória de formas distintas. Para atingir esse objetivo, foram realizadas revisão bibliográfica e entrevistas com pessoas que possuem tatuagem desse tipo e também com tatuadores especializados no gênero. As entrevistas em profundidade permitiram obter acesso aos modos pelos quais os entrevistados atribuem significados a esse tipo signo e as relações que estabelecem com suas experiências de vida. Como resultado, percebeu-se que os entrevistados compartilham o mesmo interesse pelo tema, mas, em razão da história que se deseja contar, utilizam as tatuagens com propósitos comunicacionais diferentes.

Palavras-chave: Comics Tattoo ; objeto biográfico; álbum de memória.

Abstract: - Comics tattoo as biographical object - The main purpose of this paper is to understand Comics Tattoo as a biographical object that aims to preserve and communicate memory in different ways. To achieve this goal, we carried out a bibliographic review as well as interviews with people who have tattoos of this type and tattoo artists specialized in the genre. The indepth interviews allowed gaining access to the ways in which respondents attribute meanings to this type of sign and the relationships they establish with their life experiences. As a result, it was noticed that the interviewees share the same interest in the subject, but because of the story they want to tell, they use tattoos for different communication purposes.

Keywords: comics tatto; biographical object; memory album.

\section{Introdução}

Toda tatuagem é um tipo de objeto comunicacional que está diretamente relacionado à preservação da memória. Nomes e rostos de pessoas queridas, datas de nascimento ou de conquistas alcançadas, cenas de acontecimentos, símbolos religiosos ou de agremiações

1 Este texto integra pesquisa que recebeu o auxílio Programas Regulares-Auxílio à Pesquisa da Fapesp. 
esportivas e, até mesmo, figuras da moda servem como registro de uma vida vivida ou que se deseja mostrar como sendo vivida - ou de tendências de uma época ou local. Para Fruh \& Thomas (2012), ao estabelecer relações entre o passado, presente e futuro, a tatuagem acaba por colaborar com a formação da identidade, que, em certa medida, está associada à problemática da memória. Como afirma Martino (2010), a elaboração de discursos e narrativas, verbais ou não verbais, sobre nossa identidade é "resultado de nossas experiências significadas transformadas em parte de nossa memória. [...] é o discurso escolhido e montado por nós para representar um 'eu' diante dos outros".

Assim como colaboram para determinar as fronteiras individuais e de grupo (POLLAK, 1992), os discursos e narrativas verbais ou não verbais do indivíduo tatuado revelam sua perspectiva sobre o mundo e sobre si mesmo (FALKENSTERN, 2012). É sob esse ponto de vista que, neste estudo, nos apropriamos do conceito de objeto biográfico, como desenvolvido por Bosi (2003), para entender a tatuagem como um objeto comunicacional que serve para preservar e narrar momentos específicos de uma vida particular e de um tempo, colaborando, assim, com a representação de uma perspectiva particular de mundo; e, no caso específico da Comics Tattoo, para entender a tatuagem como um objeto midiático, que serve não só para narrar momentos de uma vida e de uma época, mas também para demonstrar como os signos da cultura midiática participam na constituição das histórias de vida dos indivíduos.

Com base nesses pressupostos, o presente texto objetiva compreender a Comics Tattoo - um estilo específico de tatuagem que se apropria de imagens de personagens de histórias em quadrinhos e de desenhos animados - como um objeto biográfico que visa a preservar e comunicar a memória. Para isso, foram realizadas revisão bibliográfica, com base em textos das áreas de filosofia e psicologia social, e entrevistas em profundidade 2 com pessoas que possuem tatuagens de personagens e com tatuadores especializados em Comics Tattoo (Figura 1). As entrevistas permitiram compreender como os entrevistados atribuem significados a esse tipo signo e as relações que estabelecem com suas experiências vividas. Percebeu-se que existem diferentes modos de uso dos personagens como tatuagens e essas formas de uso são definidas em razão da história que se deseja contar. Nas entrevistas realizadas foram identificados dois tipos básicos: o álbum de família, em que predomina a lógica da singularidade como forma de narrar momentos específicos da vida; e o álbum de coleção, em que predomina a lógica da coletividade com vista a preservar a memória da infância. Em outro trabalho (CARDOSO, 2017), caracterizamos os diferentes tipos de Comics Tattoo e propusemos a metáfora do álbum para dois tipos. Neste, entendemos que tanto o álbum de família quanto o álbum de coleção atuam como objetos biográficos, já que servem à preservação de momentos da vida e/ou à manutenção de exemplares que se considera importantes. Esses modos de utilização de

2 No período de setembro de 2015 a novembro de 2016 foram entrevistadas 13 pessoas, entre tatuadores especializados no estilo Comics Tattoo e portadores de tatuagens de personagens. Além desses, foram entrevistados um especialista em licenciamento de personagem e um pesquisador da linguagem de HQ. Neste artigo são apresentados dados de 7 entrevistados. 
figuras midiáticas, permanentemente gravados na própria pele, atestam como os signos da cultura midiática podem ser profundamente incorporados às vidas das pessoas.
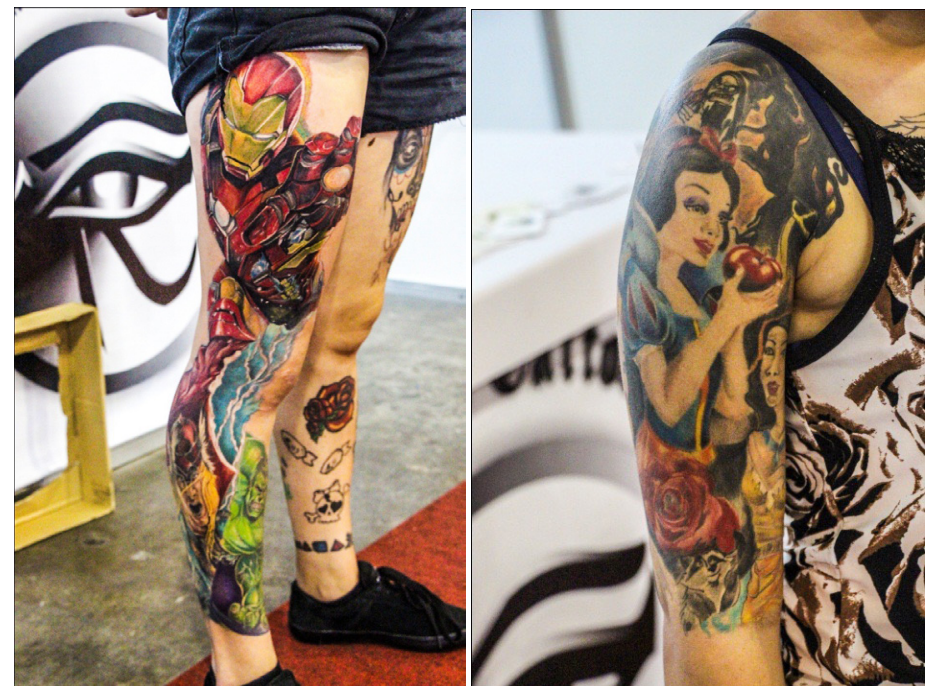

Fig.1. A/B. Comics Tattoo.

Fonte: do autor, 2015.

\section{O álbum como objeto biográfico - memória e identidade}

Certos objetos, com os quais convivemos diariamente, além de, muitas vezes, possuírem um caráter utilitário, servem para definir nossa identidade. Para Bosi (2003, p. 25-26), desejamos que, com o passar dos anos, esses objetos permaneçam ao nosso redor, pois "eles nos dão um assentimento à nossa posição no mundo, à nossa identidade; e os que estiveram sempre conosco falam à nossa alma em sua língua natal". Entre esses objetos estão as peças de mobiliário passadas de pais para filho, os suvenires de viagens e os álbuns de fotografias.

De acordo com Bosi (2003), Violette Morin chama esses objetos que estão incorporados à vida de seus proprietários de objetos biográficos. O álbum de família "representa uma experiência vivida, uma aventura afetiva" (BOSI, 2003, p. 26). Para essa autora, a permanência dessas referências afetivas nos dá a sensação de continuidade, a ideia de que nos mantemos como sempre fomos ou a persistente lembrança do que fomos e ainda gostaríamos de ser.

Bosi (ibidem) toma como base Walter Benjamin para defender a ideia de que as fotografias de familiares que se espalham pela sala de visita têm que ser lidas fenomenologicamente: 
A foto do parente que já morreu pode ser contemplada pelo dono da casa como um preito sentido à sua memória. Estamos, portanto, em pleno reino de privacidade, tout court, que interessa e afeta a relação pessoal, íntima, do recordado e do recordador. A foto daquele mesmo parente poderia ter sido colocada com o espírito de quem faz uma exposição que interessa o olhar do outro - o olhar social. Por essa visada a foto sobre o móvel carece de uma aura afetiva própria e ganha outra aura, a do status, onde estão embutidos valores de distinção, superioridade, competição, na medida em que o morto foi uma pessoa importante, logo dotada de valor-de-troca. Um olhar inibe o outro: são abordagens qualitativamente excludentes. O objeto ou é biográfico, ou é signo de status e, como tal, entraria para a esfera de uma 'intimidade', entre aspas, ostensiva e publicável, que já faz parte da História das Ideologias e das Mentalidades (ibidem, p. 28-29).

O álbum de família, que preserva a memória de gerações por meio dos registros fotográficos de eventos considerados mais importantes - como casamento, batismo, formatura, viagem etc. -, transita entre uma e outra posição: ao ser exibido em ocasiões especiais para um grupo pequeno de pessoas autorizadas, exerce a função de signo de status; ao ser folheado pelas próprias pessoas que, direta ou indiretamente, fazem parte da história contada por meio dos retratos, assume a função de objeto biográfico. Muitos álbuns desse tipo reúnem não só fotografias, mas também outros tipos de objetos que documentam os eventos vividos, como, por exemplo: convites; ingressos; fragmentos de objetos diversos.

O álbum de coleção, ainda que tenha outra finalidade, reunir objetos de uma mesma categoria - moedas; selos; rótulos etc. -, assemelha-se nos modos de fruição. Exerce a função de signo de status ao ser exibido publicamente e se assume como objeto biográfico ao permitir ao colecionador rememorar momentos de conquista de cada objeto e/ou épocas relacionadas a eles.

Em ambos os casos, as escolhas feitas, sobre os objetos que devem ou não compor um álbum de memória, os critérios utilizados na seleção dos objetos que devem ou não ser preservados, tanto servem para contar a história vivida de quem os conserva quanto para contar histórias de um período, uma época, um lugar.

Conforme afirma Pollak (1992), a memória é seletiva. Para ele, existem elementos da memória individual e/ou coletiva que estão relacionados a acontecimentos, que envolvem sujeitos e lugares:

Esses três critérios, acontecimentos, personagens e lugares, conhecidos direta ou indiretamente, podem obviamente dizer respeito a acontecimentos, personagens e lugares reais, empiricamente fundados em fatos concretos. Mas pode se tratar também da projeção de outros eventos [...]. (ibidem, p. 202-203) 
Ou seja, os indivíduos mantêm a memória do vivido ou do que sabem - ou acreditam - ter sido vivido. Como lembra Pollak (ibidem, p. 204), a memória "é, em parte, herdada, não se refere apenas à vida física da pessoa".

Entretanto, essa memória, no momento em que é articulada e expressa, passa por processos de ressignificações, que "podem tanto ser conscientes como inconscientes. O que a memória individual grava, recalca, exclui, relembra, é evidentemente o resultado de um verdadeiro trabalho de organização" (ibidem, p. 204). E é justamente esse caráter, individual e social, de reconstrução da memória e ressiginifcação das imagens, que permite acreditar que exista uma estreita ligação entre a memória e o sentimento de identidade.

\footnotetext{
[...] é, a imagem que uma pessoa adquire ao longo da vida referente a ela própria, a imagem que ela constrói e apresenta aos outros e a si própria, para acreditar na sua própria representação, mas também para ser percebida da maneira como quer ser percebida pelos outros (ibidem).
}

Pollak (ibidem) acredita que a construção da identidade, nesse sentido, está relacionada ao sentimento de individualidade, tanto da consciência do corpo quanto da ideia de pertencimento a um grupo; à percepção de continuidade do tempo, nos sentidos físico, moral e psicológico; e à crença em uma constituição coerente do indivíduo.

\begin{abstract}
Podemos portanto dizer que a memória é um elemento constituinte do sentimento de identidade, tanto individual como coletiva, na medida em que ela é também um fator extremamente importante do sentimento de continuidade e de coerência de uma pessoa ou de um grupo em sua reconstrução de si. (ibidem)
\end{abstract}

Entretanto, o autor sugere que a construção da identidade se desenvolve em constantes negociações com os outros. Isto é, a identidade, assim como a memória, não deve ser compreendida como algo natural a uma pessoa ou um grupo. Ao contrário disso, por ser "um fenômeno que se produz em referência aos outros, em referência aos critérios de aceitabilidade, de admissibilidade, de credibilidade" (ibidem), a identidade e a memória estão sujeitas a mudanças em função dos outros.

\title{
Comics Tattoo e a preservação da memória
}

Quando um indivíduo faz uma tatuagem, independentemente da motivação, ele pretende preservar a memória de algo que considera importante por meio do desenho de: nomes ou retratos de pessoas queridas; frases ou símbolos religiosos; escudos de agremiações esportivas ou insígnias de grupos políticos; sinais da moda ou imagens das mídias. Nesse último grupo, estão as Comics Tattoos, tatuagens de personagens de histórias em quadrinhos e desenhos animados, em que a memória remete geralmente à infância (CARDOSO, 2017). 
Em entrevistas realizadas no período de setembro de 2015 a novembro de 2016, com pessoas que possuem tatuagens, predominantemente, do gênero Comics Tattoo e com tatuadores especializados nesse gênero, foi possível verificar que a decisão por fazer uma tatuagem de personagem de história em quadrinhos ou desenho animado passa, em certa medida, pelo desejo de manter a memória da infância. Nesta pesquisa, partimos da hipótese de que, em sua grande maioria, os portadores de Comics Tattoo são aficionados por histórias em quadrinhos e desenhos animados desde a infância e, na idade adulta, ainda colecionam as revistas onde são veiculados os seus personagens favoritos e, muitas vezes, colecionam também filmes, livros, figurinhas, miniaturas, camisetas e todo tipo de objeto que estampa a imagem desses personagens. Assim, para eles, não é estranho trazer gravada no corpo a imagem de seu personagem favorito.

Um dos entrevistados, que chamaremos aqui de Portador $\mathrm{A}\left(\mathrm{PA}^{3}\right)$, reforça essa hipótese ao declarar: "a decoração da minha casa é feita basicamente por super-heróis [...] e eu acho que eles estão presentes o tempo inteiro na minha vida [...], em todos os lugares que eu vou e encontro alguma coisa de super-heróis eu tento comprar". PA, até o momento da entrevista, possuia oito tatuagens de super-heróis (Figura 2).

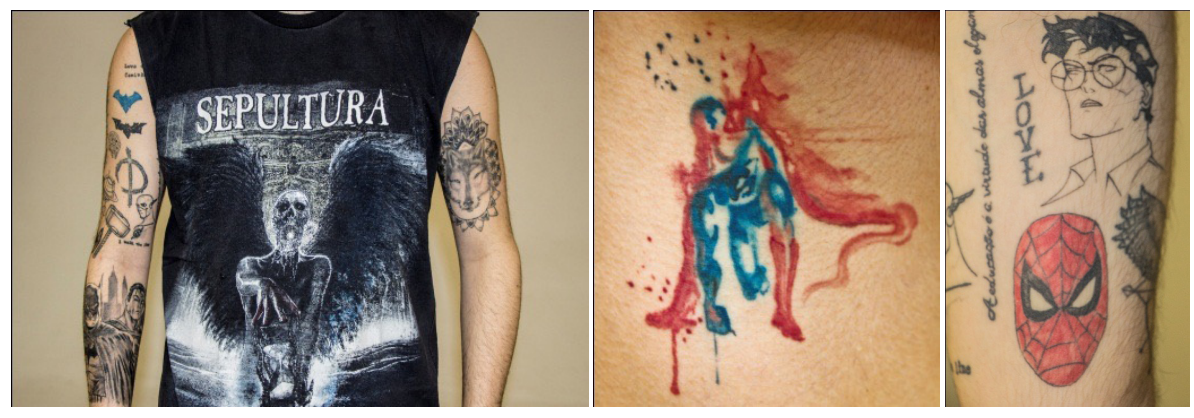

Fig.2. A/B/C. Série de fotos de PA com imagens de personagens. Fonte: do autor, 2015.

Outro entrevistado, Portador B ( $\left.\mathrm{PB}^{4}\right)$, que possui mais de 120 tatuagens de personagens de desenhos animados (Figura 3), é proprietário de um estabelecimento comercial decorado com objetos diversos relacionados ao tema: bonecos e brinquedos de personagens, pôsteres de seriados televisivos e histórias em quadrinhos etc. 

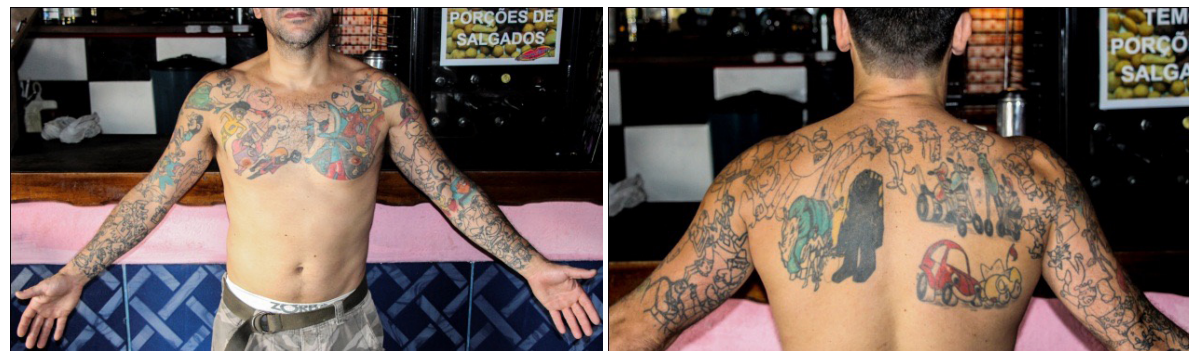

Fig. 3. A/B. Série de fotos de PB com imagens de personagens. Fonte: do autor, 2015

Esse perfil do portador de Comics Tattoo é citado pelos tatuadores entrevistados - que chamaremos de "T + ALFABETO". O artista de tatuagem TA5 , que é especialista no gênero, relata que as pessoas que fazem tatuagens desse tipo se identificam com os personagens desde a infância. De acordo com ele, são pessoas que gostam de desenhos, acompanham séries e assistem a filmes. $\mathrm{TB}^{6}$, que é proprietário de um estúdio de tatuagem especializado em Comics Tattoo, afirma que esse público consome quadrinhos, RPG e mangá, entre outros gêneros de ficção seriada. Outro tatuador entrevistado, $\mathrm{TC}^{7}$, conta que seus clientes são pessoas que sempre gostaram de histórias em quadrinhos e desenhos animados e que agora, na idade adulta, podem dizer: "Não quero nem saber se você vai tirar sarro do meu Batman ou Super-Homem. É meu". O entrevistado descreve esse tipo de consumidor da seguinte forma: "[...] Imagine um cara que cresceu vendo desenho a vida toda, [...] você não acha que ele vai ter esse vínculo o resto da vida?". Como se pode observar, para esses profissionais, muito do interesse que se mantém na idade adulta inicia na infância.

Reforçando essa crença, PA e PB, em seus depoimentos, relatam que o interesse pelos personagens está diretamente ligado às suas infâncias e que a decisão de tatuar no corpo esses personagens foi motivada justamente pelo desejo de preservar lembranças do passado: "[...] eu fui fã de desenho animado, eu achava que, assim, o lance do desenho [...] me fazia dar muita risada, então eu ficava contente [...]" (PB); "[...] eu acho que foi uma maneira de lembrar uma fase da minha vida. [...] toda fase tem uma parte boa e uma parte ruim, e a parte ruim nos ajuda a lembrar do que podemos melhorar [...]. Então, eu acho que toda tatuagem tem uma história" (PA).

A manutenção de uma história, para Fruh e Thomas (2012), só é possível porque toda tatuagem exerce uma função de ancoragem, que permite unificar o passado ao presente. No caso do portador de tatuagem de personagem, tudo indica que é o desejo de ancorar a memória de acontecimentos relacionados à infância ou, até mesmo, a memória do próprio contexto que envolve a época e o local de suas infâncias.

5 Entrevista realizada em $1^{\circ}$ de novembro de 2016.

6 Entrevista realizada em $1^{\circ}$ de novembro de 2016.

7 Entrevista realizada em 27 de julho de 2016. 
Além de estarem relacionadas a traços particulares ou fases de uma vida, as tatuagens tendem a revelar vínculos coletivos, pois, de acordo com Pavan e Silva (2010, p. 209), "no tipo de tatuagem há a eleição de imagens que estão permeadas pela relação de afetividade e cumplicidade com os produtos culturais massificados pela mídia". Ou seja, no caso dos personagens apresentados em narrativas seriadas veiculadas pelas mídias, antes de assumirem um valor simbólico no corpo humano, tais figuras já expressam comportamentos ou valores morais. Os aspectos estéticos, éticos e o valor biográfico das imagens, para esses indivíduos, justificam o ato de marcar o corpo. Tais aspectos, segundo eles, não são determinados por tendências, mas sim por fatores intimamente relacionados às suas histórias de vida.

Assim como outros indivíduos tatuados, o portador de Comics Tattoo faz uso de um repertório para falar de si e sobre o que pensa do mundo. Contudo, essa forma de apropriação de elementos da cultura midiática revela que seus afetos e experiências de vida se sobrepõem às tendências estilísticas impostas pelo mercado de tatuagem e pela sociedade, como declara PB: "Não era uma questão de moda, eu queria fazer alguma coisa que me lembrasse... que me fizesse feliz".

Contudo, de acordo com Lee (2012), as histórias e os eventos narrados por meio das tatuagens não são sempre verdadeiros. Na realidade, nem precisam ser necessariamente verdadeiros. Assim como a identidade é uma espécie de narrativa em curso, uma construção de sentido formada ao longo do tempo, como defende Hall (2000), as histórias e eventos narrados são concebidos por meio da memória e do imaginário do portador.

Para Smith (2012, p. 110), as memórias nunca serão permanentes como as tatuagens: "como podemos recordar o passado tal como aconteceu quando o passado já não existe e nosso ato de lembrança é necessariamente sempre em fluxo?". Para ele, mais do que narrarem o passado, as tatuagens dizem "quem nós somos agora", ou, até mesmo: quem nós queremos parecer ser agora.

Ao tentar explicar ou justificar o sentido da figura tatuada, o sujeito constrói, por meio de um conjunto de associações, suas próprias narrativas (PEREZ, 2014). Apontando para a figura do Superman (Figura 2B), tatuada em sua costela, e referindo-se à separação dos pais, PA revela: "eu também fui de ferro [referindo-se à expressão 'Homem de Aço']" a imagem aquarelada de Superman mostra o personagem se levantando após uma provável queda. Contudo, Lee (2012) acredita que tanto faz se as histórias contadas são verdadeiras ou não. Afinal, grande parte das histórias contadas por meio de registro fotográfico, por exemplo, não necessita de um "valor de verdade". Para esse autor, o mais importante em uma tatuagem é contar uma história, simbolizar algo importante na vida do portador. Quando isso não acontece, ela apresenta-se como um elemento meramente decorativo.

De modo geral, para grande parte dos portadores de tatuagens, essas imagens não são meros ornamentos, elas são elementos constitutivos do self, estão firmemente ligadas à identidade pessoal. A identidade, sob esse ponto vista, é estruturada por meio de 
narrativas que estão relacionadas a determinadas experiências de vida, também lembradas em forma de narrativas. Assim, a construção de narrativas apresenta-se em um equilíbro instável entre algo que se pretende dizer sobre si e o modo como são lembrados os eventos ou fatos vividos. Por um lado, elas informam da pessoa que nos tornamos e, por outro, são construídas de modo que não se tornem pura fantasia (FRUH; THOMAS, 2012).

Assim, PA e PB narram suas infâncias e contam, ou criam, suas histórias de como essas tatuagens estabelecem relações com o passado. Eles tentam, por meio de referências da cultura midiática, preservar elementos do passado e construir suas identidades. Contudo, ainda que compartilhem o mesmo interesse por essa temática e aparentem certo comportamento comum, ao tirar as imagens de seus contextos e atribuir a elas um novo sentido, PA e PB apresentam duas propostas distintas de uso dos personagens como tatuagens: o álbum de família e o álbum de coleção.

\section{Comics Tattoo como álbum de memória}

Da mesma maneira que uma série de imagens é gravada no corpo como forma de preservação da memória, as Comics Tattoos remetem ao passado. São reproduções de imagens de personagens de histórias em quadrinhos ou desenhos animados, que, via de regra, falam um pouco da infância de quem as porta ou referem-se ao contexto de uma época. Quando materializados na pele, esses objetos trazem consigo não apenas a recordação de um tempo vivido, mas também a lembrança da prática de consumo dos objetos originais - revistas, filmes, brinquedos, parques, roupas etc. É nesse sentido que entendemos serem também objetos biográficos. Objetos que, habitualmente, refugiam-se na esfera da intimidade afetiva.

Assim, o portador desse tipo de tatuagem busca manter na memória momentos de sua vida ou do que acredita ter sido vivido. No caso dos laços afetivos que envolvem personagens de histórias em quadrinhos ou desenhos animados, que atravessaram a infância e ainda permanecem na memória, estabelecem-se relações desses com experiências particulares ou com informações obtidas em outras fontes, vinculadas a outros contextos. Logo, o objeto biográfico não se refere unicamente à vida vivida, mas também às ideias herdadas do contexto que envolve o objeto original (POLLAK, 1992).

No caso dos personagens de histórias em quadrinhos, as relações que se estabelecem com partes da vida ou crenças que se pretende preservar, são também definidas por relações outras, estabelecidas, em grande parte, com os conteúdos difundidos pelas mídias. Como afirma Le Goff (2003, p. 420-421), "os fenômenos da memória [...] mais não são do que os resultados de sistemas dinâmicos de organização e apenas existem na medida em que a organização os mantém ou os reconstitui".

Dessa forma, os objetos biográficos, de maneira geral, e os álbuns, de modo específico, tanto preservam a memória de um tempo vivido quanto de um passado coletivo. 
Partindo desse pressuposto, acreditamos que a tatuagem de história em quadrinhos possa também exercer a função de um álbum de memórias e, consequentemente, de um objeto biográfico. Utilizando como base os depoimentos de PA e PB, é possível relacionar esse objeto biográfico a dois tipos distintos de álbuns: respectivamente, o de família e o de coleção (CARDOSO, 2017).

PB assume estar mais preocupado com o conjunto. Ao afirmar "eu me considero um álbum", o comerciante revela que pretende tatuar o maior número de figuras possível, como um álbum de figurinhas colecionáveis. Fazendo isso, entende que conseguirá resgatar parte de sua infância. PA, por outro lado, aparenta seguir a lógica do álbum de família. Prefere preservar as lembranças do passado e registrar eventos do presente com vista à manutenção da memória futura.

\begin{abstract}
Eu gosto de escolher minuciosamente as tatuagens. Tipo, uma por uma pra definir determinadas fases da minha vida, o que representa cada uma, porque eu me lembro do que se passava na minha vida; [...] quando o braço estiver fechado, haverá várias tatuagens em todos os lugares, cada uma representará uma coisa [...], porque cada uma representa uma fase da minha vida e é isso que eu acho mais interessante em tatuagem. (PA)
\end{abstract}

Se para PB o conjunto de figuras representa a época de sua infância, para PA cada imagem isolada representa um momento específico de sua vida. Se para PA interessa o registro em si, que permite narrar uma história vivida, ao outro interessa acumular o maior número possível de imagens que permite retratar um tempo preciso. Utilizando a metáfora do álbum de coleção, próprio para a colagem de selos ou figurinhas, PB desvela outra metáfora, a do álbum de família, próprio para colagem de retratos, anotações e registros de eventos vividos. Ambos os álbuns, de família ou coleção, atuam, em certos momentos, como álbum de memória. Logo, como objeto biográfico.

Entretanto, sabemos que essas imagens também servem a outro propósito, atuar como objeto de status. Alguns tatuadores, como TC, relatam que na definição do lugar do corpo a ser tatuado sempre se considera a visibilidade da figura. Sob essa lógica, ao fazer para a visada do outro, a tatuagem acaba se prendendo também a padrões estéticos predominantes. TB também destaca essa função ao lembrar que há uma "tendência de mercado", "algo que está na moda no momento". Discurso também repetido por TD que acredita existirem fases, tendências no mercado de tatuagem que, de certo modo, influenciam na escolha da imagem e do local do corpo a ser tatuado.

Contudo, ainda que no momento da definição da figura ou do local do corpo a ser tatuado sejam levadas em consideração as tendências do mercado, isso não anula o fato de as Comics Tattoo exercerem, ao olhar íntimo do portador, a função de objeto biográfico. Ou seja, ainda que os diferentes olhares sejam excludentes, como afirma Bosi (2003),

8 Entrevista realizada em 6 de outubro de 2016. 
um mesmo objeto pode exibir-se em um determinado momento como objeto de status e, em outro, como objeto biográfico.

O que se quer dizer é que, como álbum, análogo ao de família ou ao de coleção, a tatuagem de personagem guarda concomitantemente a função de objeto biográfico e objeto de status. Ou melhor, ainda que exerça a função de objeto de status, todo álbum é, em sua essência, um objeto biográfico. Ainda que seja utilizado para a visada externa, ele é constituído para guardar a memória de um tempo passado ou de uma vida vivida; ainda que em sua grande maioria essas mesmas imagens estejam destinadas a uma visada pública, social, elas falam um pouco da infância daqueles que as portam; reportam a uma época, trazendo consigo não apenas lembranças vividas, mas também as recordações coletivas, de um tempo passado. Assim, residem na esfera da intimidade afetiva. Como afirma TA, ao apontar para as suas próprias tatuagens: "as minhas tatuagens eu sei que são uma história que eu vivo e são o que eu já vivi... são a história de minha vida, todinha contada nos meus desenhos".

\section{Considerações finais}

Em outros trabalhos (CARDOSO, 2017; 2016; 2015), temos procurado defender a ideia de que os personagens de histórias em quadrinhos e desenhos animados participam na constituição das identidades individuais coletivas e, em muitos casos, estão intimamente integrados às memórias dos indivíduos.

Quando esses signos tomam a forma de tatuagem, atuam como objetos comunicacionais que servem não só à preservação da memoria individual, mas também da memória coletiva. Os discursos e narrativas que se originam dessas imagens são resultados não só das recordações de experiências vividas, mas também das lembraças relacionadas às práticas coletivas de consumo dos produtos midiáticos: assistir a desenho animado em grupo, jogar bafo com figurinhas colecionáveis, trocar revistas usadas etc. Nesse sentido, entendemos a Comics Tattoo como um tipo específico de objeto biográfico que acaba por desempenhar a função de preservar momentos de uma vida, narrar uma visão de mundo e resguardar elementos da cultura midiática de um período.

De modo geral, as imagens dos personagens de histórias em quadrinhos e desenhos animados sempre estiveram associadas ao objeto álbum: como álbum de figurinhas, no modelo de álbum de coleção; ou em decoração de aniversário infantil, como registro fotográfico em álbum de família, por exemplo. Nos dois casos, diferente da Comics Tattoo, atendendo aos interesses do mercado de licenciamento.

No contexto específico da Comics Tattoo, seja na forma de álbum de família ou de álbum de coleção, tal objeto preserva lembranças particulares da infância, narra momentos específicos da vida, reafirma identidades, ao mesmo tempo em que preserva memórias coletivas da cultura midiática. Em qualquer uma dessas situações, naturalmente, 
os personagens referem-se mais à trajetória ou às memórias da pessoa tatuada do que a seu universo de origem, às revistas de histórias em quadrinhos ou às animações televisivas. Ou seja, a reprodução dos personagens no corpo ressignifica os personagens e ultrapassa os interesses comerciais.

Ainda assim, a comunicação midiática está íntimamente interligada ao ambiente cultural da Comics Tattoo. As escolhas feitas, as figuras que devem ou não compor o álbum no corpo, em certa medida, são herdadas, são coletivas, compartilhadas por meio de séries animadas, revistas impressas, brinquedos e brincadeiras de criança. A cumplicidade com os produtos culturais massificados pela mídia revela ao mesmo tempo vínculos coletivos e afetos íntimos. Assim, a Comics Tattoo fala um pouco da infância de quem a porta, refere-se ao contexto de uma época e resgata a prática de consumo dos objetos originais.

Por meio da Comics Tattoo, a memória é mediadora entre a comunicação midiática e as lembranças pessoais e coletivas. Nesse sentido, as tatuagens que reproduzem imagens de personagens passam a se comportar como um objeto biográfico, ponte entre o vivido e o perene que instiga a lembrança de tempos passados. Álbum vivo, ambulante, que respira e rememora.

João Batista Freitas Cardoso é professor no Programa de Mestrado da Universidade Municipal de São Caetano do Sul (PMC-USCS) e nas Universidades Mackenzie; é lider do grupo de pesquisa "O signo visual nas mídias". É doutor em Comunicação e Semiótica pela PUC-SP, com pós-doutorado pela ECA-USP.

jbfcardoso@uol.com.br

\section{Referências}

BOSI, E. O tempo vivo da memória - ensaios de Psicologia Social. São Paulo: Ateliê Editorial, 2003.

CARDOSO, J. B. Comics Tattoos: normas e singularidades. Revista E-Compós. V. 20, N. 1, janeiroabril. São Paulo: Compós. Disponível em: http://www.compos.org.br/seer/index.php/e-compos/ article/viewFile/1329/926. Acesso em 13/10/2017.

. No muro, na roupa, na pele: o personagem na paisagem urbana. Revista Comunicação \& Inovação, São Caetano do Sul, v. 17, n. 4, maio-agosto. 2016. pp. 73-91. Disponível em: http://seer. uscs.edu.br/index.php/revista_comunicacao_inovacao/article/view/3915. Acesso em 13/10/2017.

There's life in other systems: the Comic Character outside narratives. In: LENT, J. A. (ed.). International Journal of Comic Art. V. 17, N. 2, Fall/Winter. Drexel Hill: IJOCA, 2015. pp. 547-560.

FALKENSTERN, R. C. Illusion of permanence: tattoos and the temporary self. In: ARP, R. (ed.). Tattoos - philosophy for everyone: I ink, therefore I am. Oxford: Wiley-Blackwell, 2012. pp. 96-108.

FRUH, K; THOMAS, E. Tattoo you: personal identity in ink. In: ARP, R. (ed.). Tattoos - philosophy for everyone: I ink, therefore I am. Oxford: Wiley-Blackwell, 2012. pp. 83-95. 
HALL, S. A identidade cultural na pós-modernidade. Rio de Janeiro: DP \& A. 2000.

LEE, W. L. Never merely "there": tattooing as a practice of writing and telling stories. In: ARP, R. (ed.). Tattoos - philosophy for everyone: I ink, therefore I am. Oxford: Wiley-Blackwell, 2012. pp. 151-164.

LE GOFF, J. História e Memória. Campinas: Editora da Unicamp, 2003.

MARTINO, L. M. S. Comunicação \& Identidade - quem você pensa que é? São Paulo: Paulus, 2010.

PAVAN, M. A; SILVA, J. C. Tatuagem: cultura de massas e afirmação subjetiva incorporadas. Signos do Consumo, v. 2, 2010. pp. 01-16.

PEREZ FONSECA, A. L. Cuerpos tatuados, "almas" tatuadas: nuevas formas de subjetividad en la contemporaneidad. Revista Colombiana de Antropologia, v.45, jan. - jun., 2009. pp. 69-84. Disponível em: http://icanh.gov.co/recursos_user/cuerpos_tatuados.pdf. Acesso em 13/10/2017.

POLLAK, M. Memória e Identidade Social. Estudos Históricos, Rio de Janeiro, v. 5, n. 10, 1992. pp. 200-212. Disponível em: http://bibliotecadigital.fgv.br/ojs/index.php/reh/article/view/1941/1080. Acesso em 13/10/2017.

SMITH, C. My tattoo may be permanent, but my memory of it isn't. In: ARP, Robert (ed.). Tattoos philosophy for everyone: I ink, therefore I am. Oxford: Wiley-Blackwell, 2012. pp. 109-120.

Artigo recebido em 12 de julho e aprovado em 15 de outubro de 2017. 